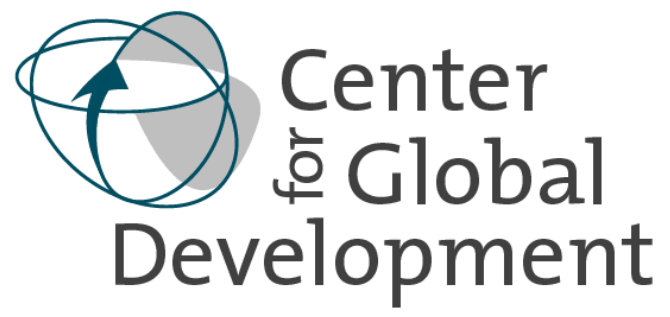

Financial Crises and Poverty in Emerging Market Economies

By William Cline

\title{
Abstract
}

This study examines the impact of the principal financial crises in emerging markets in recent years on the incidence of poverty in the countries in question. The growth impact is first identified by comparing average per capita growth in the two years prior to the crisis to that in the crisis year and the following year. The poverty impact is then measured by applying the elasticity of poverty with respect to growth. Alternative estimates consider results of surveys in the relevant periods, where available.

The central estimate is that some 40 to 60 million people were placed in poverty by the financial crises affecting Mexico (1995), Thailand and Indonesia (1997), Korea and Russia (1998), Brazil (1999), and Argentina and Turkey (2001), compared with total population of 800 million in these eight countries. By far the largest impact was in Indonesia, because of the severe income decline and the large base population in poverty. Those economies with relatively better crisis management (Mexico, Thailand, Korea, Brazil, Turkey) are found as a group to have experienced considerably milder growth and poverty shocks than those with unsuccessful management (Indonesia, Russia, and Argentina). These results underscore the importance of appropriate crisis resolution for both national and international policymakers.

A technical appendix examines the elasticity of poverty with respect to growth on the basis of the underlying income distribution forms, for both the Pareto and lognormal distributions. The analysis establishes for the Pareto and confirms for the lognormal that the absolute magnitude of this elasticity is positively related to the ratio of average per capita income to the poverty line threshold, and negatively related to the degree of inequality as measured by the Gini coefficient. 


\title{
Financial Crises and Poverty in Emerging Market Economies"
}

\author{
William Cline ** \\ Center for Global Development
}

Working Paper No. 8

June 2002

\footnotetext{
* Paper prepared for R. Albert Berry Festschrift, Munk Centre for International Studies, University of Toronto, 19-20 April 2002. For comments on earlier drafts I am grateful to Nancy Birdsall, William Easterly, Martin Ravallion, Edwin M. Truman, and John Williamson.

${ }^{* *}$ Senior Fellow, Center for Global Development and Institute for International Economics, wcline@cgdev.org
} 
For the emerging market economies, the past seven years have been dominated by a series of major financial and/or currency crises. These crises have temporarily derailed economic growth. Economic growth is the surest engine for lifting populations out of poverty. This paper reviews the severity of growth disruption from these crises and presents estimates of their impact on the incidence of poverty in the affected economies. Although the analysis here does not address how such crises can be averted or ameliorated in the future, these estimates may help provide a sharpened sense of the stakes involved.

\section{The Crises}

The round of major financial crises began with Mexico at the end of 1994. An intensive and broader phase then followed with the collapse of currencies and banking systems in Thailand, Indonesia, and Korea in 1997-98. Russia's default and currency collapse in August 1998 was next, followed by Brazil's currency collapse in January 1999. The final two major crises in this period were those of Turkey and Argentina, both beginning in late 2000 and extending until the present. ${ }^{1}$

Each of these crises has been marked by a sharp collapse of the currency (even, finally, in currency-board Argentina). Most episodes (the principal exception being Brazil) have also been marked by a severe banking sector crisis, in part reflecting pressure on debtors from higher local currency cost of debt denominated in foreign currency as well as from interest rate increases adopted to defend currencies.

This will not be the place to diagnose the causes of these crises or to set forth proposals on how such crises can be avoided or abated in the future. At least one summary observation seems useful, however. Domestic political coherence has been a key factor determining the severity and persistence of the economic collapse associated with each crisis. Where the domestic polity has suffered from extreme weakness, in some cases including the dissolution of a sitting government, the crisis has tended to spiral into deeper recession and default on external debt. This has been the case in Indonesia (where the Suharto government fell), Argentina (where President de la Rua was forced to resign), and Russia (where the Yeltsin government was in its last phases of inefficacy). ${ }^{2}$ In contrast, where there have been the political underpinnings for decisive policy reaction, the crises have tended to be less severe and shorter-lived, and have not led to forced default and forgiveness of external debt

1 Other crises in this period included those of Ecuador, Pakistan, and Ukraine. They are excluded from the analysis here, in part because of their smaller size and less significant implications for the financial system, but also in part because of the more unique political origins of their difficulties than in most of the cases reviewed here.

${ }^{2}$ Russia was, however, an exception to more severe growth impact in countries with more incoherent political conditions, though it was no exception to the outcome of external debt default with forgiveness. In fact average per capita growth in Russia in 1999-2000 was somewhat higher than in 1997-98. This partly reflected much stronger oil prices after their fall in 1998, but the outsized per capita growth of 2000 (8.6 percent) also reflected greater policy coherence under the new Putin regime as well as the beginnings of firm-level enterprise reform in the less uncertain environment. It also reflected the growth stimulus from import substitution induced by the sharp devaluation, especially in 1999. 
(Mexico, Korea, Thailand, Brazil, and tentatively Turkey). ${ }^{3}$

\section{The Impact on Growth}

Figure 1 shows the path of per capita income growth before, during, and after the year of the crisis for each of the eight major cases reviewed here. ${ }^{4}$ In every case there was a decline in per capita growth in the crisis year, most dramatically by 15 percent in the case of Indonesia. In all but one case, there was a rebound in per capita growth, usually to a positive figure, in the year after the crisis, most notably in Korea where the per capita rebound reached 10 percent in 1999. The exception is Argentina, where the projected recession this year will be even worse than last year's.

Figure 1

3 This will also not be the place to argue the direction of causality regarding the political outcome and economic circumstances, except to say that it seems fairly obvious that, for example, an Argentina with a government debt to GDP ratio of about 50 percent would have been nowhere near the pariah it became for international investors if it had not experienced a sequence of political unravelings that began with the resignation of the Vice President from the coalition government in October 2000 and extended through fiscal bickering with opposition provincial governors in the final months of 2001.

4 The crisis year (year zero in the figure) for each country is as follows: Mexico, 1995; Thailand, Indonesia, Korea, and Russia, 1998; Brazil, 1999; Argentina and Turkey, 2001. This timing focuses on the first full year after the onset of the crisis. Whether by chance or for some systematic reason, most of these crises began in the fourth quarter of the preceding year (but Thailand's erupted in July, Russia's in August). The first-full-year measure allows for some lag from the crisis outbreak to production results. 


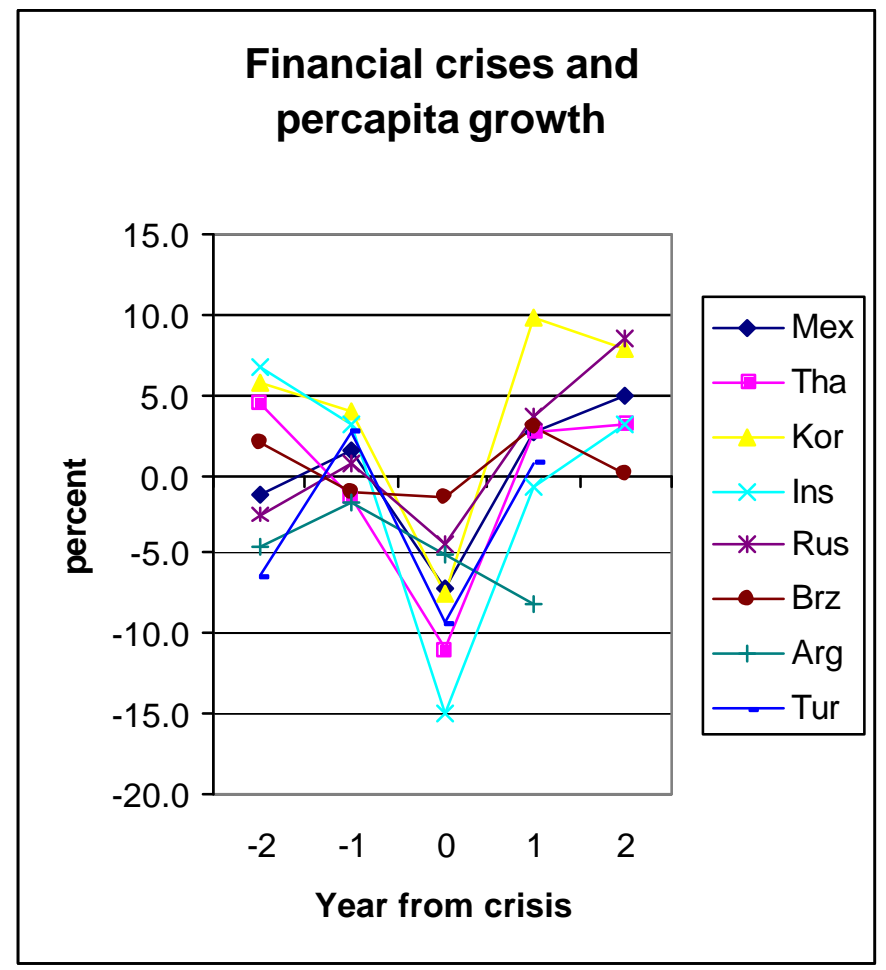

Table 1 presents a rough estimate of the growth impact of the crises by comparing the average per capita growth rate during the year of the crisis (0) and the year after (1) against the average rate in the two years prior to the crisis. ${ }^{5}$ For the five countries where there has been more successful crisis resolution (again giving still-unfinished Turkey the benefit of the doubt), average per capita growth fell by 1.7 percentage points from before to during and immediately after the crisis. For the three unsuccessful resolution cases, the average decline was considerably larger at 5.2 percentage points, although this was dominated by the steep drop in Indonesia. ${ }^{6}$

\section{The Impact on Poverty}

The incidence of poverty is sensitive to economic growth. A number of international sources suggest that a reasonable central empirical estimate for the elasticity of poverty incidence with respect to per capita growth is around -2. For example, if 35 percent of households are below the poverty line, then per capita growth of 1 percent is likely to reduce the number in poverty by 2 percent, or from 35 percent to 34.3 percent of total households. Thus, the World Bank (2001, p. 47) finds that "On average, every additional percentage point of growth in average household consumption reduces that share [of people living on less than $\$ 1$ a day] by about 2 percent." Summary data presented by

5 For Argentina and Turkey growth in year " 1 " after the crisis is a forecasted rate for 2002.

${ }^{6}$ It could be argued, however, that Russia was not an "unsuccessful" case with respect to the focus here - growth, even though it was from the standpoint of debt and financial stabilization. Reclassifying Russia to the successful from the unsuccessful group would widen the gap between the two to average twoyear per capita growth impact of -1.3 percent versus -8.0 percent, respectively. 
Easterly for about 150 periods in 65 developing countries also show approximately this elasticity. ${ }^{7}$ Statistical estimates by Ravallion and Chen (1997) working with the same data at a detailed level place the poverty elasticity in a range of -1.6 to -2.6 , if the poverty threshold is 50 percent of average income, and -0.95 to -1.3 , if it is set at 75 percent. $^{8}$

Table 1

Crisis impact on per capita growth (a)

\section{A. Favorable resolution cases}

$\begin{array}{lr}\text { Mexico } & -2.4 \\ \text { Thailand } & -0.4 \\ \text { Korea } & -3.7 \\ \text { Brazil } & 0.3 \\ \text { Turkey (?) } & -2.4 \\ \text { average } & -1.7\end{array}$

B. Unfavorable resolution cases

Indonesia

Russia

Argentina

average
$-12.7$

0.5

$-3.4$

$-5.2$

a. Change from average in two years prior to crisis to average in crisis and subsequent year.

Annex A further considers the expected elasticity of poverty with respect to growth from an analysis of two underlying functional forms for the income distribution: the Pareto and log-normal distributions. The analysis shows that in both, the poverty elasticity is larger in absolute terms when the initial degree of inequality is lower, and when the target poverty-income threshold is lower relative to average income. The summary elasticity of -2 used here is approximately consistent, for example, with a Pareto distribution in which the poverty threshold is set at one-half average household income and the initial income concentration shows a Gini coefficient of 0.5 ; or, in a log-normal distribution, when the

7 For four groupings of country-periods from slowest- to fastest-growing, the percent change in poverty ranges from 24 percent annually in the group with -9.8 percent average annual growth to -6 percent annual change in the group with +8.2 percent annual growth, yielding a simple regression coefficient of -1.66 (t-statistic -3.9) for the poverty elasticity. Calculated from Easterly, 2001, p. 13.

8 The larger absolute values are for the full data set, while the smaller ones exclude Eastern Europe and Central Asia where there was a particularly large surge in poverty incidence as per capita incomes fell during the post-1990 transition. 
poverty threshold is 40 percent of average income and the Gini coefficient is 0.4 (table A-1, Annex A).

The poverty elasticity in turn provides a basis for obtaining a rough idea of the poverty impact of the financial crises of recent years. (Actual post-crisis sample survey data on income distribution are available only for three of the cases, Mexico, Thailand, and Indonesia, as discussed below). Thus, if we apply the two-year reduction in the per capita growth rate of 1.7 percent annually for the successfulresolution cases in table 1, then per capita income may be estimated to have been cut by about 3.5 percent from levels it would have reached otherwise. Applying in turn the poverty elasticity of -2 , it may be calculated that the financial crises in this set of countries cumulatively increased the incidence of poverty by about 7 percent above what it otherwise would have been.

Using an international threshold of \$2 per day per capita income, and choosing the closest year prior to each crisis for which data are available, poverty incidence stood at 38 percent for Mexico (1992), 28 percent for Thailand (1996), 17 percent for Brazil (1997), less than 2 percent for Korea (1993), and 18 percent for Turkey (1994), according to World Bank estimates (World Bank, 2001, pp. 280-81 and by communication). So for this group of economies with about 400 million people, an estimated 96 million were in poverty prior to the crises. Applying the estimate of a 7 percent increase from the financial crises, approximately 7 million people were either newly thrust into poverty or prevented from emerging from poverty by the financial crises even for the five major countries with more successful crisis resolution. ${ }^{9}$

The same World Bank estimates place poverty incidence (by the same measure) at 50 percent for Indonesia in 1996 and 24 percent for Russia in 1996. For Argentina the under \$2 per day figure is not available, but by a national standard poverty incidence was 25 percent in 1991. For these three countries with a total population of 360 million, the number in poverty prior to the crises is thus estimated at 148 million. Applying the average 5.2 percent drop in per capita growth for the two years of crisis (table 1), for a 10.4 percent drop in per capita income from levels otherwise reached, and using the poverty elasticity of -2 , we can estimate that the crises boosted the incidence of poverty by about 21 percent. Thus, we may estimate that about 31 million people were moved into poverty, or prevented from escaping it, by the financial crises in the three unsuccessful-resolution cases.

The separation of the estimates into the two groups is designed to capture the broad difference between successful and unsuccessful crisis management in terms of the impact on poverty incidence. The aggregate estimates for the two groups indicate that in relative terms, the increase in poverty incidence was approximately three times as great for the unsuccessful crisis management cases as for the successful cases. An alternative approach is to focus directly on country-specific estimates, presented in table 2.

Three alternative estimates warrant consideration at the level of individual countries. The first applies the standard poverty elasticity $(-2)$ to the two-year cumulative growth impact to arrive at the percent change in poverty, and this in turn is applied to the pre-crisis number in poverty to obtain the crisis impact expressed in millions of people. The second allows for country-specific poverty

\footnotetext{
${ }^{9}$ This assumes population by income group is proportionate to households. Although poor families may tend to have more children, an offsetting factor is that larger families will tend to have more income earners.
} 
elasticities. These are based in part on Annex table A-1 (log-normal distribution case) as applied to each country's Gini coefficient and average per capita income (purchasing power parity) relative to the poverty threshold. ${ }^{10}$ Whereas the log-normal poverty elasticity estimates are plausible for those countries with relatively high inequality (Brazil, Mexico, Russia), they appear unrealistically high for the countries with lower inequality (Indonesia, Thailand, Turkey, and especially Korea). In these cases the country-specific elasticities used in table 2 are set at the upper-bound of -3.5 (95 percent confidence level) estimated in cross-country regressions by Ravallion (2001). ${ }^{11}$ A third alternative estimate may be obtained from actual survey data, which are available for the relevant periods for three countries (Mexico, Thailand, and Indonesia).

As shown in table 2, when the estimates are on a country-specific basis but retaining the standard poverty elasticity of -2 , the calculated total rises to 57 million people placed (or retained) in poverty by the crises. Over 90 percent of the total is estimated to have occurred in Indonesia alone, as the consequence of that country's largest base of population in poverty combined with Indonesia's largest recessionary impact of financial crisis. These country-specific estimates contain two anomalies, however, as the impacts for Brazil and Russia have the wrong sign. This is the result of the slight increase rather than decrease in average per capita growth in the year of crisis and year after, from the average in the two years prior to the crisis, and illustrates why the country-specific estimates may not be as reliable as the "central tendency" estimates for the two groupings. The Brazil and Russia results also reflect, however, the fact that much of the burden of the incipient crisis had already been borne by recession in the year prior to the crisis, in part as a consequence of high interest rates needed to defend an overvalued exchange rate.

The second alternative country-specific estimates are even higher, at 97 million. This result is again driven by the results for Indonesia. Even with the imposed ceiling on the elasticity (see note 11), the resulting estimate for Indonesia appears excessive, reflecting the combination of both a large cumulative income drop (25 percent) with a high poverty elasticity $(-3.5)$.

In the third, survey-based, estimates, for Mexico the World Bank data noted above report a rise in poverty incidence below $\$ 2$ per day from 37.5 percent in 1992 to 42.5 percent in 1995, an increment of 5 percentage points and proportionate rise of 13.3 percent, somewhat more than the 9.6 percent rise implied by the growth loss and the standard poverty elasticity of -2 . In Indonesia, the same source reports a rise in poverty below the same threshold from 50 percent in 1996 to 63 percent in 1999, a rise of 13 percentage points and 26 percent in proportionate terms - significantly smaller than the estimate obtained applying the standard elasticity to the cumulative 25 percent reduction in per capita income, and far smaller than the estimate when the higher country-specific elasticity is applied. Survey data for Thailand reported in Mazumdar and Son (2002) indicate an increase in poverty

\footnotetext{
10 Applying the ratio of the poverty threshold (\$730 ppp) to average per capita income, along with the country Gini coefficient (both from World Bank, 2001), and interpolating from table A-1, unrestricted country elasticities are: Mexico, -1.6; Thailand, Turkey, and Indonesia, $\approx-6$; Brazil, -1.1 ; Russia, -2.7, and Korea, $\approx-30$. (Argentina's national poverty threshold, used in the absence of poverty estimates at the international $\$ 730 \mathrm{ppp}$ level, is not reported in World Bank, 2001, so no specific elasticity estimate is made.)

11 An overstated elasticity for the lognormal function for cases where per capita income is relatively high and the Gini is relatively low is consistent with the finding in Cline (2002) that the lognormal increasingly underpredicts actual povery incidence as per capita income rises above approximately $\$ 1,000$ ppp per capita, except where the Gini coefficient is high.
} 
incidence (using a domestic definition) from 11.4 percent in 1996 to 16.2 percent in 2000, a 4.8 percentage point rise representing a 42 percent increase in proportionate terms. While these alternative estimates are significantly higher for Mexico and Thailand, they are much lower for Indonesia, reducing the total increase in poverty from 57 million to 36 million.

Table 2

Country-specific Poverty Impact Estimates

\begin{tabular}{|c|c|c|c|c|}
\hline & \multirow{2}{*}{$\begin{array}{c}\text { Growth impact } \\
\text { (percent over } 2 \text { years) }\end{array}$} & \multicolumn{3}{|c|}{ Change in poverty incidence, millions } \\
\hline & & $\mathrm{A}$ & $\mathrm{B}$ & \\
\hline Mexico & $\mid-4.8$ & 3.6 & 2.9 & 4.9 \\
\hline Thailand & -0.8 & 0.3 & 0.5 & 2.9 \\
\hline Korea & -7.4 & 0.1 & 0.2 & n.a. \\
\hline Brazil & 0.6 & -0.3 & -0.2 & n.a. \\
\hline Turkey & -4.8 & 1.1 & 1.9 & n.a. \\
\hline Indonesia & -25.4 & 52.6 & 92.1 & 27.3 \\
\hline Russia & 1.0 & -0.7 & -0.9 & n.a. \\
\hline Argentina & -3.4 & 0.6 & n.a. & n.a. \\
\hline Total & & 57.3 & 97.1 & 35.9 \\
\hline
\end{tabular}

A: standard elasticity B: country-specific elasticity $\quad$ C: survey

n.a. Not available; column A estimate applied for total

In sum, considering both the successful/ unsuccessful pooled estimates of table 1 and the country specific estimates of table 2 (all three variants), the recent financial crises placed in poverty a central estimate of approximately 40 million to 60 million people, and possibly as many as almost 100 million. By far the largest impact occurred in Indonesia, especially in the extreme estimate (Table 2, variant B) where a high poverty elasticity is combined with this country's large income decline and large base of population in poverty.

One question that may be raised about the elasticity-based estimates is whether the per capita growth impact of the crises was distributionally neutral, as this approach assumes. The bias from this standpoint could be upward, as capital incomes are more likely to be procyclical than labor incomes. Indeed, Birdsall and Haggard (2000, pp. 19-22) find that "Though most of Indonesia's poor live in rural areas, the effects of the [1997-98] crisis were concentrated in the urban economy." The "urban strivers" comprising workers with primary education and small business owners were the most affected; construction and industry were the sectors hit hardest (for example, because of high interest rates adopted to defend the rupiah); and per capita consumption fell more for the top 20 percent of households (by 23 percent) than for the lowest 40 percent (a 10 percent decline). Even so, it is unclear that there is much if any overstatement in the poverty-impact calculations here from this standpoint, because what is relevant is the incidence of a slip below the poverty line for those near it. ${ }^{12}$

12 In particular, if we interpolate the Birdsall-Haggard estimates for Indonesia, the per capita income 
Another qualification of the results is that the poverty-impact estimate is only defined over a certain period of time, and with resumed growth after the crises some of those newly placed into poverty presumably will have exited from it. Similarly, use of the before-during comparison of growth rates for the crisis impact might be said to overstate the role of the crises on grounds that the pre-crisis rates may have reflected unsustainable growth that was postponing a day of reckoning. Moreover, simple before-after comparison of growth rates is only a rudimentary means of gauging the growth impact of the crises (as is most evident in the wrong-signed estimates for Russia and Brazil). For these various reasons, the estimates should be viewed primarily as providing a broad benchmark rather than precise measures.

\section{Conclusion}

The financial crises in emerging markets in recent years at least temporarily increased the incidence of poverty by some 40 million to 60 million people (and possibly as many as 100 million), compared to what otherwise could have been expected, out of a total population of 800 million among the 8 major countries concerned. A large part of this poverty impact occurred in Indonesia alone.

The growth and poverty impact was much worse in the cases of unsuccessful resolution than in the cases of successful resolution (Mexico, Korea, Thailand, Brazil, and prospectively Turkey). For the latter group poverty incidence probably rose about 7 percent, whereas for the former it probably rose about 21 percent as the consequence of the crises, although these should be seen as only rough estimates.

These findings underscore the importance of improved domestic policies and international practices for the purpose of minimizing the occurrence of such crises in the future. They also emphasize the large stakes for the international community in helping insure that where financial crises do occur, the combined effect of temporary external support and domestic adjustment measures is such as to maximize the chances of successful crisis resolution. Successful resolution has been characterized by less severe and shorter recessions, as well as by avoidance of rupture with the financial markets from default and forced forgiveness of external debt. Unsuccessful resolution has generally been characterized by deeper and longer recessions, more severe banking crises, and debt default and forced forgiveness. Consideration of the poverty impact underscores the importance of seeking successful resolution of those crises that do occur and of minimizing the frequency of such crises. Political stability is a key determinant of the scope for avoiding severely unsuccessful outcomes.

decline of those near a mid-distribution poverty line would have been in the vicinity of 15 percent, which is larger than the group-average 10.4 percent decline applied to the group of three "unsuccessful" countries (table 1) although smaller than the Indonesia-specific estimate of 25 percent (table 2). 


\section{Annex A}

The Elasticity of Poverty with Respect to Growth ${ }^{13}$

The expected elasticity of poverty incidence with respect to per capita income, and hence the percent change in the number of poor with respect to distributionally neutral per capita economic growth, can be derived from the functional form for income distribution. For this purpose, this Annex uses two popular distributions that have been found to provide good empirical fits: the Pareto and lognormal distributions. The absolute magnitude of the "poverty elasticity" is found in both distributions to be greater when the poverty threshold is lower relative to average income, and smaller when the initial degree of income inequality is higher. The central range of -2 used for the elasticity in the main text is consistent with a range of plausible values for these two parameters under these two distributions. Nonetheless, the elasticity shows a substantial variability, especially in the Pareto distribution in which it rises explosively as the poverty threshold is reduced beyond about one-third of average income.

\section{The Pareto Distribution}

In the Pareto distribution, income is distributed as:

$$
\text { 1) } N=A y^{-b}
$$

where $N$ is the number of households with income above level $y$, subject to $y \geq y_{o}$ and $b>1$ (see e.g. Cline, 1972). In this function, the larger the value of parameter $b$, the more equal the distribution of income (as the tail of households with higher income drops off more rapidly). Define $y_{p}$ as the income level at the poverty threshold. Define $w_{p}$ as the cumulative fraction of households at incomes below this level, or the "headcount" poverty measure. Then considering that the entire population has income above $y_{o}$, we have:

$$
\begin{aligned}
& \text { 2) } w_{p}=\frac{A y_{0}^{-b}-A y_{p}^{-b}}{A y_{0}^{-b}} \\
& =1-\left[\frac{y_{p}}{y_{0}}\right]^{-b}
\end{aligned}
$$

We seek the elasticity of $w_{p}$ with respect to neutral growth. This elasticity may be obtained in two conceptual steps. The first step is to consider the elasticity of the number of poor with respect to

13 An earlier version of this note was prepared in a comment on Morley (1992), presented at the Brookings Institution Conference on Income Distribution in Latin America, July 16, 1992, Washington D.C. David Roodman provided crucial analytical research assistance. The derivation of the log-normal elasticity closely follows Bourguignon (2002). I am indebted to Francois Bourguignon for helpful discussion of the differences between the Pareto and log-normal cases. 
the income level used as the cutoff for defining poverty. The second step is then to recognize that this same elasticity is the negative of the elasticity relating the number in poverty to the per capita growth rate. Essentially, the same number of households will enter newly into poverty whether there is a 1 percent increase in the defined poverty threshold income or a 1 percent across-the-board drop in per capita income (assuming a continuous income concentration function like the Pareto distribution).

Pursuing the first step, the elasticity of a dependent variable with respect to an independent variable is given by the first derivative divided by the ratio of the dependent to independent variable (i.e. marginal/average). From equation (2), the derivative of the fraction of population in poverty $\left(w_{p}\right)$ with respect to the income level defining the poverty line $\left(y_{p}\right)$ is:

3) $\partial w_{p} / \partial y_{p}=\left[\frac{b}{y_{0}^{-b}}\right] y_{p}^{-b-1}$

Dividing this marginal relationship by the average ratio $w_{p} / y_{p}$, we have the elasticity:

$$
\begin{gathered}
\text { 4) } \varepsilon_{w}=\frac{\left[b /\left(y_{0}^{-b}\right)\right] y_{p}^{-b-1} y_{p}}{1-\left[y_{p} / y_{0}\right]^{-b}} \\
\text { or } \\
\varepsilon_{w}=\frac{b}{\left[y_{p} / y_{0}\right]^{b}-1}
\end{gathered}
$$

So far the elasticity developed here refers to the proportionate change in the coverage of the poor for a proportionate change in the threshold income level. This elasticity is positive: the higher the threshold, the larger the fraction of the population defined as poor. As noted above, the corresponding elasticity with respect to growth refers to movement of the threshold in the opposite direction. The number of poor changes by the same amount whether their income rises by 1 percent or the poverty threshold declines by 1 percent. But as the direction of change for $y_{p}$ is now negative, the elasticity of poverty incidence with respect to income growth should be the same absolute size as the elasticity with respect to poverty income threshold but with the opposite sign. ${ }^{14}$

Thus,

14 Kakwani (1993) provides a generalized decomposition of the change in poverty incidence into that stemming from change in average income (growth) and change in income distribution, and considers alternative measures of poverty. For the same metric as adopted here, the "headcount" fraction $(H)$ of population below a specific poverty income $(z)$, he identifies the growth elasticity of poverty $\left(?_{H}\right)$ under unchanged distribution as: $?_{H}=[-z f(z)] / H$ where $f(z)$ is the probability distribution function of income $x$ at $x=z$. It can be shown that when the distribution is the Pareto function (equation 1), the Kakwani result is equivalent to that in equation 5) here. 
5) $\varepsilon_{w}{ }^{g}=\frac{-b}{\left[y_{p} / y_{0}\right]^{b}-1}$

As developed in Cline (1972, 228), the Gini coefficient of income concentration for the Pareto distribution has the value $\mathrm{G}=1 /[2 b-1]$. In view of the appearance of the poverty threshold $y_{p}$ in the denominator, for a given Gini coefficient and hence parameter $b(=[1+G] / 2 G)$ the elasticity decreases in absolute value as the poverty threshold increases. ${ }^{15}$

Recent estimates of Gini coefficients tend to be somewhat lower for Asia (in the vicinity of 0.35 for such economies as Korea, India, Indonesia, and Thailand), somewhat higher for Latin America (around 0.55 for Brazil, Mexico, and Venezuela), and intermediate for emerging Europe (about 0.45 for Russia and Turkey) (World Bank, 2001, pp. 280-81). With a Gini coefficient of 0.5, for example, the value of $b$ in the Pareto function is 1.5 .

The other parameter needed in equation 5) is the ratio of the poverty threshold income $\left(y_{p}\right)$ to the minimum income in the society $\left(y_{o}\right)$. A conventional definition of the poverty threshold is twice the income required to purchase a minimum basket of food. If it is assumed that the minimum income would need to cover more than food alone, this would mean the poverty income threshold is somewhat less than twice the minimum income. At the same time, too high a poverty threshold would mean an unrealistically high aspiration for household income in view of the economy's resources. In the Pareto distribution, the income level at quantile ? in the distribution (where ? is the cumulative fraction of households) will have the property that $\mathrm{y}_{?} / \mathrm{y}_{\mathrm{o}}=(1-?)^{-1 / \mathrm{b}} \cdot{ }^{16}$ Applying this relationship, and setting the poverty threshold $y_{p}$ at, for example, the $40^{\text {th }}$ percentile in the cumulative income distribution, we have: $y_{p} / y_{o}=0.60^{-1 / 1.5}=1.41$. This illustrative level would meet both objectives of a realistic aspiration for the poverty threshold (which is set below the median income) and an amount that is somewhat less than twice the minimum income (and hence consistent with twice the minimum food budget cost). Using this threshold and applying an illustrative Gini coefficient of 0.5 , equation 5) yields a poverty elasticity of 2.2 , consistent with the stylized elasticity of -2 used in the main text.

As may be seen from equation (5), the elasticity will be lower the higher is the ratio of the poverty threshold to the minimum income level observed. Thus, if an ambitiously high standard is set for identifying the poor, the coverage of the poverty group will shrink only relatively slowly as growth takes place. The sensitivity of the elasticity to the target poverty threshold is examined below.

Although equation 5) provides a point estimate of the poverty elasticity for a given inequality parameter (b) and poverty threshold relative to minimum income $\left(y_{p} / y_{o}\right)$, it is desirable to state the elasticity in a normalized form that removes the absolute minimum income. Otherwise examination of the sensitivity of the elasticity to the inequality parameter will be misleading. Thus, if $b$ in equation 5) is

15 This is confirmed empirically in the estimates of Ravallion and Chen (1997) cited in the main text.

16 By definition, at income level $y_{\text {? }}$ cumulative households with income below this level are $N^{*}-A y_{\text {? }}^{-b}$ where $N^{*}$ is the total population $\left(=A y_{o}^{-b}\right)$. This corresponds to the bottom fraction of households (quantile) of ? $=\left(N^{*}-A y_{?}{ }^{-b}\right) / N^{*}=1-A y_{?}^{-b} / N^{*}=1-A y_{?}^{-b} / A y_{o}^{-b}=1-\left[y_{?} / y_{o}\right]^{-b}$. Rearranging and taking the root of both sides gives the text equation. 
reduced so that the degree of inequality rises, then unless $y_{o}$ is correspondingly changed there will be a larger amount of total income in the system (average income must rise with more households at higher income levels). Reformulating the elasticity as a function of the ratio of the poverty threshold to average income accomplishes normalization. Defining $\mu$ as mean income in the system, the minimum income turns out to be: ${ }^{17}$

6) $y_{o}=\frac{b-1}{b} \mu$

Substituting 6) into 5), the poverty elasticity becomes:

7) $\varepsilon_{w}^{g}=\frac{-b}{\left[\frac{y_{p}}{\mu} \frac{b}{b-1}\right]^{b}-1} \mu$

The properties of this elasticity in terms of its sensitivity to the two parameters $b$ and $y_{p} / \mu$ are discussed below, along with the corresponding results for the log-normal function.

\section{The Log-normal Distribution}

Another functional form that has been found to be perhaps even more representative of income distributions is the log-normal distribution. In this form (see Aitchison and Brown, 1963, p. 8), the natural logarithm of income has a normal distribution. The probability distribution function of income $y$ is: ${ }^{18}$

8) $f(y)=\frac{1}{\sqrt{2 \pi} \sigma y} e^{-\frac{(\ln y-\delta)^{2}}{2 \sigma^{2}}}$,

where the total integral of 8) is unity, $e$ is the base of the natural logarithm, $\delta$ is the mean of $\ln y$, and $\sigma$ is the standard deviation of the logarithm of $y$. To normalize, divide income by the mean of income to get

17 Total income is: $\quad \int_{y_{o}}^{\infty} y|d N / d y|=\int_{y_{o}}^{\infty} b A y^{-b}=\frac{b}{b-1} A y_{o}^{1-b} . \quad$ Total population is: $A y_{o}^{-b}$.

Dividing, average income is: $\mu=\frac{b}{b-1} y_{o}$. Rearranging gives 6).

18 As Aitchison and Brown (1963) begin with the cumulative distribution function which is normal in $\ln$ $y$ rather than $y$, and obtain the probability distribution function as the derivative of the cumulative function, the term $y$ in the denominator of 8) results from taking the derivative of the logarithm of $y$. This term is absent from the more familiar normal probability distribution of $y$ rather than $\ln y$. 
$x=y / \mu$. Following Bourguignon (2002), the log-normal distribution of this relative income may be expressed as a standard normal distribution $\psi$ with mean 0 and standard deviation of unity, as follows:

9) $f(x)=\frac{1}{\sigma x} \psi\left(\frac{1}{\sigma} \ln x+\frac{\sigma}{2}\right)$.

Correspondingly, the cumulative density function, or cumulative probability that relative income is less than or equal to a given level $x$, is the integral of 9) up to the given relative income level. Again this may be expressed in terms of the cumulative distribution function of the standard normal, yielding:

$$
\text { 10) } F(x)=\Pi\left(\frac{1}{\sigma} \ln x+\frac{\sigma}{2}\right)
$$

The headcount fraction of population in poverty is the integral of the probability distribution function up to (or value of the cumulative density function at) the poverty income threshold $y_{p}$, or:

11) $w_{p}=F\left(x_{p}\right)$

The elasticity of the poverty head count with respect to distributionally neutral growth is given by the percent change in the head count for a 1 percent change in mean income, or:

12) $\varepsilon_{p}^{g}=-\frac{d F\left(x_{p}\right) / d \mu}{F\left(x_{p}\right) / \mu}$

By definition the derivative of the cumulative density function $F(x)$ is the probability distribution function $f(x)$. By the chain rule,

13) $\varepsilon_{p}^{g}=\frac{-f\left(x_{p}\right)\left[d x_{p} / d \mu\right]}{F\left(x_{p}\right) / \mu}$

Using the transform to the standard normal, we have:

14) $\varepsilon_{p}^{g}=\frac{-\frac{1}{\sigma x_{p}} \psi\left(\frac{1}{\sigma} \ln x_{p}+\frac{\sigma}{2}\right)\left[-\frac{y_{p}}{\mu^{2}}\right]}{\prod\left(\frac{1}{\sigma} \ln x_{p}+\frac{\sigma}{2}\right) / \mu}=\frac{\frac{1}{\sigma} \psi\left(\frac{1}{\sigma} \ln x_{p}+\frac{\sigma}{2}\right)}{\prod\left(\frac{1}{\sigma} \ln x_{p}+\frac{\sigma}{2}\right)}$

Using the "hazard ratio" defined as the ratio of the probability density function to the cumulative density function or $\lambda(\ldots) \equiv \psi(\ldots) / \Pi(\ldots)$, rewriting 14) confirms Bourguignon's (2002) result that the poverty elasticity with respect to growth is: 
15) $\varepsilon_{w}^{g}=\frac{1}{\sigma} \lambda\left(\frac{1}{\sigma} \ln \frac{y_{p}}{\mu}+\frac{\sigma}{2}\right)$

Equation 15) shows that in the log-normal distribution, as in the Pareto distribution case shown in equation 7), the poverty elasticity is a function of the level of the poverty threshold relative to average income $\left(y_{p} / \mu\right)$ and the degree of inequality (which, in the log-normal, is a function of the parameter $\sigma$ ). The final section of this Annex discusses the behavior of the elasticity in response to each of these influences under the two alternative distributional forms.

III. Size of the Poverty Elasticity as a Function of Poverty Threshold and Inequality

To evaluate the poverty elasticity under the two alternative distributions, it is first necessary to identify the correspondence between the inequality parameter in each (- $b$ in the Pareto, $\sigma$ in the lognormal) and a standard measure of inequality, the Gini coefficient. This correspondence has been discussed above for the Pareto distribution. For the log-normal distribution, $G=2 \Pi(\mathrm{v}[\sigma / 2])-1$, where again $\Pi$ is the cumulative standard normal density function of the scalar in the parentheses; see Aitchison and Brown (1963) and Bourguignon (2002). Given Gini coefficient $G$, the implied inequality parameter $\sigma$ in the log-normal function is thus: $\sigma=2\left\{\Pi^{-1}([G+1] / 2)\right\}^{2}$, where $\Pi^{-1}(.$.$) is the inverse$ function of the cumulative standard normal distribution.

As an example, suppose that the poverty threshold stands at one-half average income, or: $y_{p} / \mu$ $=0.5$. Suppose that the Gini coefficient is 0.5 . Then based on equations 7) and 14), the Pareto distribution yields a poverty elasticity of -1.79 , and the log-normal distribution gives an elasticity of -1.1 . Table A-1 reports alternative values of the elasticity under the two alternative distributions and for a range of relevant values for the poverty threshold relative to average income and the initial degree of inequality as measured by the Gini coefficient. 
Table A-1

Poverty Elasticity as a Function of Poverty Threshold Relative to
Mean Income and Gini Coefficient

$\begin{array}{lllllll}\mathrm{z} / \mu: & 0.1 & 0.2 & 0.3 & 0.4 & 0.5 & 0.6\end{array}$

1. Lognormal distribution

\begin{tabular}{rrrrrrrr} 
Gini & \multicolumn{1}{l}{$\sigma$} & & & & & \\
0.3 & 0.3 & -25.29 & -17.95 & -13.65 & -10.65 & -8.39 & -6.61 \\
0.35 & 0.41 & -13.59 & -9.66 & -7.40 & -5.85 & -4.70 & -3.80 \\
0.4 & 0.56 & -7.26 & -5.19 & -4.03 & -3.25 & -2.66 & -2.21 \\
0.45 & 0.72 & -4.35 & -3.14 & -2.47 & -2.02 & -1.69 & -1.43 \\
0.5 & 0.91 & -2.68 & -1.96 & -1.56 & -1.30 & -1.10 & -0.95 \\
0.55 & 1.15 & -1.63 & -1.21 & -0.97 & -0.82 & -0.71 & -0.62 \\
0.6 & 1.4 & -1.06 & -0.79 & -0.64 & -0.55 & -0.48 & -0.43
\end{tabular}

2. Pareto distribution

$\begin{array}{rlllllll}\text { Gini } & \mathrm{b} & & & & & & \\ 0.3 & 2.17 & \mathrm{a} & \mathrm{a} & \mathrm{a} & \mathrm{a} & \mathrm{a} & -8.20 \\ 0.35 & 1.93 & \mathrm{a} & \mathrm{a} & \mathrm{a} & \mathrm{a} & -25.54 & -3.65 \\ 0.4 & 1.75 & \mathrm{a} & \mathrm{a} & \mathrm{a} & \mathrm{a} & -5.65 & -2.18 \\ 0.45 & 1.61 & \mathrm{a} & \mathrm{a} & \mathrm{a} & -18.03 & -2.87 & -1.47 \\ 0.5 & 1.50 & \mathrm{a} & \mathrm{a} & \mathrm{a} & -4.77 & -1.79 & -1.06 \\ 0.55 & 1.41 & \mathrm{a} & \mathrm{a} & -29.80 & -2.47 & -1.22 & -0.79 \\ 0.6 & 1.33 & \mathrm{a} & \mathrm{a} & -4.85 & -1.53 & -0.88 & -0.60\end{array}$

a. Undefined; $[(z / \mu)(b /\{b-1\})]^{\wedge} 2<1$.

The calculations reported in table A-1 confirm that the poverty elasticity with respect to distributionally neutral growth is sensitive to the initial distribution of income (Gini) and to the level of the poverty threshold relative to the mean. The Pareto function gives an extremely high sensitivity to the relative poverty threshold, and at levels below about one third (or even higher, when the Gini coefficient is low), the elasticity becomes explosive. This is because as $y_{p} / \mu$ declines toward the reciprocal of $b /(b-1)$, the bracketed term in the denominator of 7) approaches unity and the full denominator approaches zero. Even in the log-normal distribution there is considerable sensitivity to the targeted poverty threshold. Thus, with a Gini of 0.5 , the log-normal poverty elasticity is -2.7 if the threshold is only 10 percent of average income, but falls to -1.1 if the target is set at 50 percent of average income.

Finally, the table calculations confirm that the more unequal the initial income distribution, the lower the poverty elasticity. For example, if the poverty threshold is 50 percent of average income, then a country with initial inequality of $\mathrm{G}=0.4$ will have an elasticity of -2.66 in the log-normal case and 5.65 in the Pareto case. Another country with income concentration higher at $\mathrm{G}=0.5$ will have an elasticity of -1.3 (log-normal) to -1.79 (Pareto), considerably lower. The intuition here is that a more equal distribution means that all households are more tightly bunched along the distribution, so that a larger portion of them is likely to move across an arbitrary poverty line for any given percent increase in all household incomes. 


\section{References}

Aitchison, J., and J. A. C. Brown, 1963. The Lognormal Distribution (Cambridge: Cambridge University Press)

Birdsall, Nancy, and Stephan Haggard, 2000. After the Crisis: the Social Contract and the Middle Class in East Asia (Washington: Carnegie Endowment for International Peace).

Bourguignon, Francois, 2002. "The Growth Elasticity of Poverty Reduction: Explaining Heterogeneity Across Countries and Time Periods." (Washington: World Bank, February) Photocopy. Available at: http://faculty.washington.edu/ te/papers/inequality/bour.pdf.

Cline, William R., 1972. Potential Effects of Income Redistribution on Economic Growth (New York: Praeger)

Cline, William R., 2002. “Trade Policy and Global Poverty," draft manuscript (Washington: Center for Global Development and Institute for International Economics, June)

Easterly, William, 2001. The Elusive Quest for Growth: Economists' Adventures and Misadventures in the Tropics (Cambridge, Mass.: MIT Press).

Kakwani, Nanak, 1993. "Poverty and Economic Growth with Application to Côte D'Ivoire," Review of Income and Wealth, series 39, no. 2, June, pp. 121-39.

Mazumdar, Dipak, and Hyun Hwa Son, 2002. "Vulnerable Groups and the Labour Market in Thailand: Impact of the Asian Financial Crisis in the Light of Thailand's Growth Process," (Toronto: University of Toronto, April).

Morley, Samuel, 1992. "Structural Adjustment and Determinants of Poverty in Latin America," (Washington: Inter-American Development Bank, mimeographed).

Ravaillion, Martin, 2001. "Growth, Inequality and Poverty: Looking Beyond Averages" World Development, vol. 29, no 11, pp. 1803-15.

Ravallion, Martin, and Shaohua Chen, 1997. "What Can New Survey Data Tell Us about Recent Changes in Distribution and Poverty?" World Bank Economic Review, vol. 11, No. 2, May, pp. 357-82.

World Bank, 2001. World Development Report 2000-2001: Attacking Poverty (Washington: World Bank). 


\section{Center for Global Development Working Papers}

No. 1, January 2002

No. 2, January 2002

No. 3, February 2002

No. 4, March 2002

No. 5, April 2002

No. 6, May 2002

No. 7, May 2002

No. 8, June 2002
Inequality Does Cause Underdevelopment: New Evidence.

William Easterly

HIV/AIDS and the Accumulation and Utilization of Human Capital in Africa

Amar Hamoudi and Nancy Birdsall

External Advisors and Privatization in Transition Economies

John Nellis

The Cartel of Good Intentions: Bureaucracy versus Markets in Foreign Aid

William Easterly

Intellectual Property and the Availability of Pharmaceuticals in Developing Countries Jean O. Lanjouw

Winners and Losers: Assessing the distributional impacts of privatization. John Nellis and Nancy Birdsall

Commodity Dependence, Trade, and Growth: When 'Openness' is Not Enough. Nancy Birdsall and Amar Hamoudi.

Financial Crises and Poverty in Emerging Market Economies. William Cline

All CGD Discussion Papers are available on-line at www.cgdev.org. For more information, please contact Andrew Stober, astober@cgdev.org. 
